\title{
Original sat \\ A study of predictors for identification of risk of complications in patients with liver abscess
}

\author{
Satish Kumar R, Sathyanarayana B.A, Madhu Shankar L, Nataraj \\ Naidu R, Amit Gupta M, Hemanth Vupputuri
}

\begin{abstract}
Department of Surgery,

Background/Aims: Liver abscess is a significant health problem in developing countries and Kempegowda Institute of Medical Sciences and Research Centre,

K R Road, VV Puram, Bangalore, Karnataka- 560004, India. the complications associated with it are frequently fatal. Hence identification of these complications and anticipating the same will lead to reduction in the mortality and morbidity rate. Such a work will facilitate in identifying patients with risk of complications and will allow for planning of an early intervention. The aim of this study was to identify the predictors of risk of complications in patients with liver abscess. Materials and Methods: The data for this retrospective study was obtained from hospital records and included 100 patients diagnosed

Correspondence:

Dr. Satish Kumar $R$

Email: hemumbbs@gmail.com to have solitary or multiple liver abscess. Complications were defined and history, lab and radiological findings and course of treatment were observed and analyzed in correlation with occurrence of complications. A predictive scoring system was designed for 15 points by giving two points to the factors with $100 \%$ correlation and one point to other factors with strong correlation. The score was applied to a validation cohort of 114 different patients and results were noted. Results: Out of the 100 cases studied 24 cases had complications of and the predictive factors included history of alcoholism ( $>10 \mathrm{yrs}$ ), INR > 1.7, TLC > 20000/cc and pleural effusion, while other factors had a varying degree of correlation with complication occurrence. It was observed that the new scoring system was successful in identifying patients at risk of developing complications with $100 \%$ sensitivity and $93.75 \%$ specificity.

Conclusion: Management of liver abscess can be clearly defined by dividing patients into categories depending upon a new scoring system described in the study and intervention can be planned.
\end{abstract}

KEYWORDS: Liver abscess, Complications of liver abscess, Predictive score, Early identification.

\section{Introduction}

Liver abscess is an uncommon entity that has seen fairly dramatic changes in demographics, etiology, diagnosis, and treatment over the past 100 years. While the mortality from liver abscess has decreased sig-nificantly since the early $20^{\text {th }}$ century, the incidence appears to be increasing. ${ }^{3}$ Though modern diagnostics like ultrasound and computed tomography to locate and drain the abscess have reduced the mortality to
$2-12 \%$ there is still high morbidity due to the complications of liver abscess especially the amebic liver abscess. ${ }^{4,5}$ The management of liver abscess has always been a dilemma for any clinician, to decide, when to perform a therapeutic aspiration and when to avoid it. No strict criteria exist to identify patients with risk of developing complications.

Our own experiences prompted a retrospective view of cases 
admitted in a single tertiary center in Bengaluru, India. The aims of this study were to analyze the factors that have predictive value in cases of complicated liver abscess and create a scoring system for prediction of risk of complications in a case of liver abscess.

\section{Materials and methods}

The data for this retrospective study were obtained from records of patients treated for liver abscess in two clinical departments (Department of General Medicine and Department of General Surgery) at our hospital in Bengaluru, India between January 2009 and August2010, which formed the derivation cohort and January 2011 to December 2012 which formed the validation cohort. The study design and protocol were approved by the Hospital Research and Ethics Committee.

For derivation of the score a total of 100 cases diagnosed with liver abscess by clinical examination and ultrasound imaging irrespective of being single or multiple in number were considered for study and records analyzed. Inclusion criteria included any case of liver abscess irrespective of age, gender, solitary/multiple, etiology were included. Exclusion criteria included those cases, which presented with peritonitis due to rupture of liver abscess and required emergency laparotomy. Medical records were scrutinized for demographic characteristics, underlying medical conditions, initial clinical manifestations, laboratory findings, imaging and microbial findings, treatment and overall morbidity and mortality.

The following conditions comprised complications a) intra abdominal rupture of abscess and peritonitis, b) septic shock/ multi organ dysfunction syndrome (MODS), c) cholangitis, d) rupture into pleural cavity e) rupture into pericardium and g) death.

\section{Clinical, imaging and laboratory parameters}

Patient data were collected from records of all patients attending casualty and admitted as in-patients, irrespective of age/gender/ background and or/ socio-economic status. The patients were evaluated and followed up according to the following protocol. Detailed history of patients was analyzed. Laboratory parameters included complete hemogram, liver function tests (LFT's), prothrombin time and INR, serology for amoebic antigen, stool for occult blood and other routine investigations like chest X-ray were also analyzed. The patient was followed up clinically, everyday, LFT and ultrasonography abdomen repeated every third day.

Preliminary ultrasonography of abdomen and pelvis was done on the day of presentation. The patient was conservatively managed. Repeat ultrasound / CT scan abdomen and pelvis were done immediately if the patient's condition neither improved nor worsened after three to four days

All patients were administered antibiotics intravenously initially upon admission, metronidazole, $40 \mathrm{mg} / \mathrm{kg} /$ day in divided doses for 14 days. If aspiration was done and pus revealed growth of organisms / patient did not improve after 3 days of treatment then a full course of the appropriate antibiotics were instituted $\left(3^{\text {rd }}\right.$ generation cephalosporin + aminoglycoside). Patients were examined daily for clinical improvement. Improvement in pain, fever, anorexia, and hepatomegaly were considered parameters of successful treatment. The mean hospital stay was recorded. Patients with abscesses that were slow to resolve on followup imaging often required longer courses of therapy and hospitalization. Cure was defined as improvement clinically with subsidence of fever, and local signs, symptoms, decrease in WBC count and follow-up ultrasonography showing reduction in size $<3 \mathrm{~cm}$ in diameter with no evidence of relapse.

If the patient developed any complications like ruptured liver abscess in to any serosal cavity, the patient was immediately taken up for surgery (laparotomy drainage or laparoscopic drainage). The pus was sent for gram's stain and culture and sensitivity analysis.

Complications considered were intra-abdominal rupture and peritonitis, septic shock and MODS, cholangitis, pleural rupture, pericardial rupture and death. Case fatality was defined as death during hospitalization. Multiple factors in various dimensions like age, gender, history of alcoholism, previous history of abscess, duration of onset, etc., lab investigations like total leukocyte count [TLC], random blood sugar [RBS], hemoglobin levels [Hb], serum bilirubin level [S.Bil], serum albumin levels [S.Alb], prothrombin time [PT] and serum alkaline phosphatase levels [ALP] on presentation were studied along with radiological findings like pleural effusion on chest X-ray, location, size and singularity or plurality of abscess on ultrasonography were studied after careful review of literature. ${ }^{1-7,12,13,15}$ Depending on the factors associated with complications after careful analysis a predictive score was designed wherein two points each were given for factors with $100 \%$ association with complications and one point each for factors strong correlation with complications with statistical significance. The score is depicted in the Table $\mathbf{1 .}$ 
Table 1: Predictive score for risk of complications in a patient with liver abscess.

\begin{tabular}{lc}
\hline Factors & Points \\
\hline Age $>50$ years & 1 \\
History of Alcoholism & 2 \\
$\bullet>10$ years & 1 \\
$\bullet>5$ years & 1 \\
Onset $<7$ Days & 2 \\
Total leukocyte count $>20,000 / \mathrm{Cm}^{3}$ & 1 \\
Serum albumin $<2.0 \mathrm{mg} / \mathrm{dl}$ & 1 \\
Serum alkaline phosphatase $>300$ IU & 2 \\
INR $>1.7$ & 1 \\
Pleural effusion on CXR & 1 \\
Solitary liver abscess & 2 \\
Subcapsular location of abscess/ & \\
Bilobar abscess on Ultrasonography & 1 \\
Size of abscess $>200 \mathrm{cc}$ & 15 \\
Total
\end{tabular}

History of alcoholism was considered as per 1992 National Longitudinal Alcohol Epidemiologic Survey: Lifetime abstainers were people who had never consumed 12 or more $(12+)$ alcoholic drinks in any one year. Former drinkers were people who have consumed $12+$ drinks in at least one year but not in the past year. Current drinkers were people who consumed $12+$ drinks in the past year. Only Current and former drinkers as per this classification were considered as having history of alcoholism.

The above score was applied to a validation cohort of 114 cases treated for liver abscess at the same institute between January 2011 to December 2012 in a retrospective manner and the results expected and the actual results were compared.

\section{Statistical analysis}

Descriptive statistical analysis was done. Chi-square/ Fisher Exact test has been used to find the significance of study parameters on categorical scale between two groups. Ap value $<0.05$ has been considered as significant.

\section{Results}

The derivation cohort included 89 males and 11 females, with a mean age of 46 years ranging from 19 to 75 years. Early presentation was seen in $40(40 \%)$ patients (<7days). Sub-acute presentation (between seven days to 2 months) was seen in 57 patients and those with chronic duration (more than) 2 months in 3 cases. 80 (80\%) were alcoholic out of which 79 cases were males and one was female. Amongst them $31 \%$ had more than
10 years history of alcoholism. The most common initial manifestations were abdominal pain (100\%) and fever (94\%).

Majority of the patients $(72 \%)$ had WBC count more than 11,000. Twenty-nine percent patient had high sugars ( $>200 \mathrm{mg} / \mathrm{dL})$. Anemia was seen in $44 \%(\mathrm{Hb}<10 \mathrm{~g} / \mathrm{dL})$ patients. A low serum albumin $(<2 \mathrm{~g} / \mathrm{dL})$ in $25 \%$, high ALP $(>300 \mathrm{IU} / \mathrm{L})$ in $44 \%$, high serum bilirubin $(>4 \mathrm{mg} / \mathrm{dL})$ in $43 \%$ and a prolonged PT (>20seconds) in $29 \%$ patients. Of the 100 cases analyzed 24 cases developed complications. The list of complications are shown in Table 2. The correlation of various factors in all the patients and in patients who developed complications and their statistical significance are shown in Table 3. Table 4 and Figure 1 shows the ROC curves and logistic regression data for important parameters like INR, TLC and serum albumin.

Of the above factors studied those factors whose correlation with complicated cases was statistically significant were taken to create a score and the predicting scoring system thus created had two points each for the four factors correlating

Table 2: List of complications and Number of patients developing complications.

\begin{tabular}{lc}
\hline Complication & No of Patients \\
\hline Intra abdominal rupture and peritonitis & 21 \\
Septic shock /MODS & 9 \\
Cholangitis & 5 \\
Rupture into the pleural cavity & 4 \\
Pericardial rupture & 0 \\
Death & 0 \\
\hline Total & 24 \\
\hline
\end{tabular}

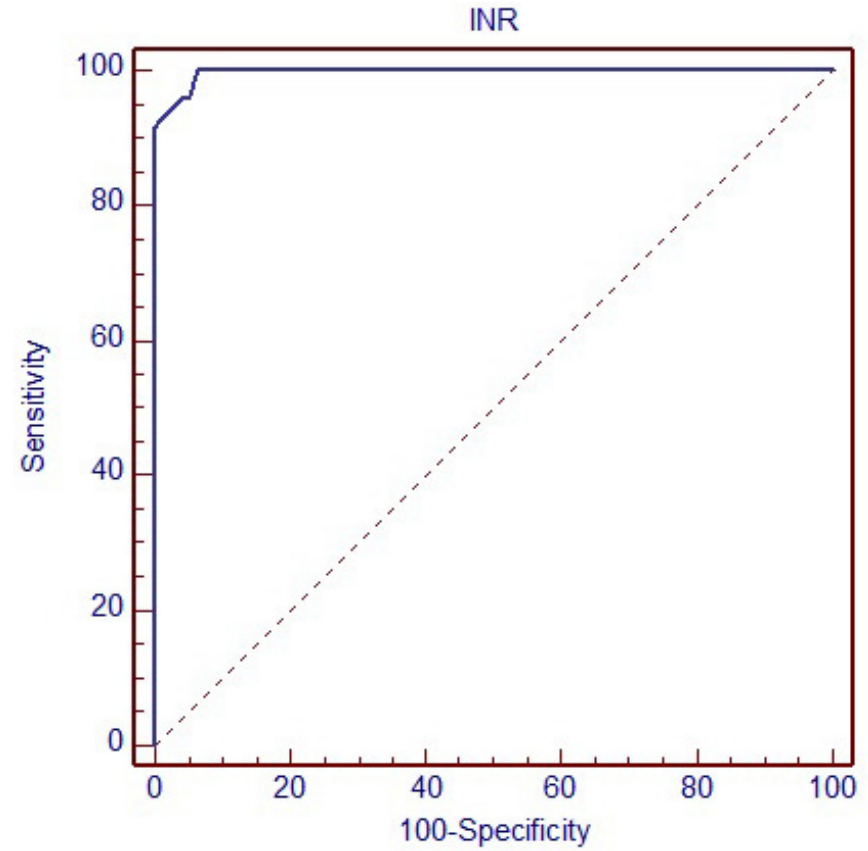

Figure 1: ROC curves for INR in complicated cases 
Table 3: Correlation of various factors with complications in liver abscess and their statistical significance. (C.I-95\% Confidence Interval of the proportion)

\begin{tabular}{|c|c|c|c|}
\hline Factor & Overall Correlation & Correlation in complicated cases & P Value \\
\hline Age $>50$ & $40 \%$ (C.I $36.6 \%-45.3 \%)$ & $87.5 \%$ (C.I $66.54 \%-96.71 \%$ ) & $<0.05$ \\
\hline \multicolumn{4}{|l|}{ History of Alcoholism } \\
\hline - $>5$ yrs & $75 \%$ (C.I $65.16 \%-82.88 \%$ ) & $31 \%$ (C.I- $22.34 \%-41.14 \%$ ) & $<0.05$ \\
\hline - $>10$ Yrs & $100 \%$ (C.I $82.83 \%-100 \%$ ) & $100 \%$ (C.I $82.83 \%-100 \%$ ) & $<0.05$ \\
\hline $\begin{array}{l}\text { Recurrent Liver Abscess } \\
\text { (H/o Previous Admission for liver abscess) }\end{array}$ & $21 \%($ C.I-13.75\%-30.53\%) & $12.5 \%$ (C.I $3.29 \%-33.46 \%)$ & $>0.05$ \\
\hline Duration of Onset $<7$ Days & $40 \%$ (C.I-30.48\%-50.3\%) & $75 \%($ C.I52.95\%-89.4\%) & $<0.05$ \\
\hline Total Leukocyte count $>20,000$ & $39 \%$ (C.I-29.56\%-49.3\%) & $100 \%$ (C.I $82.83 \%-100 \%$ ) & $<0.05$ \\
\hline Random Blood Sugar $>200$ & $29 \%$ (C.I $20.58 \%-39.06 \%$ ) & $25 \%$ (C.I-10.6\%-47.05\%) & $>0.05$ \\
\hline Hemoglobin $<10 \mathrm{mg} / \mathrm{dl}$ & $44 \%$ (C.I-34.2\%-54.26\%) & $41.66 \%$ (C.I-22.8\%-63.06\%) & $>0.05$ \\
\hline Serum Total Bilirubin $>4 \mathrm{mg} / \mathrm{dl}$ & $43 \%$ (C.I-33.27\%-53.28\%) & $70.83 \%$ (C.I- $48.75 \%-86.56 \%)$ & $>0.05$ \\
\hline Serum Albumin $(<2.0 \mathrm{mg} / \mathrm{dl})$ & $25 \%($ C.I-17.12\%-34.84\%) & $87.5 \%$ (C.I $66.54 \%-96.71 \%$ ) & $<0.05$ \\
\hline INR $>1.7$ & $29 \%$ (C.I $20.58 \%-39.06 \%$ ) & $100 \%$ (C.I $82.83-100 \%)$ & $<0.05$ \\
\hline Alkaline Phosphatase >300 IU/dl & $44 \%$ (C.I $34.2 \%-54.26 \%$ ). & $83.33 \%$ (C.I $61.81 \%-94.52 \%)$ & $<0.05$ \\
\hline Pleural Effusion on Chest Xray & $57 \%(\mathrm{CI} 46.72-66.73)$ & $100 \%$ (C.I $82.83-100 \%)$ & $<0.05$ \\
\hline $\begin{array}{l}\text { Sub Capsular Abscess/ Bi lobar } \\
\text { abscess on Ultrasonography }\end{array}$ & $31 \%$ (C.I $22.34 \%-41.14 \%$ ) & $79.1 \%$ (C.I $57.3 \%-92.07 \%)$ & $<0.05$ \\
\hline Abscess Size $>200 \mathrm{~cm}^{3}$ on ultrasonography & $67 \%$ (C.I-56.79\%-75.88\%) & $95.8 \%$ (C.I $76.88 \%-99.78 \%$ ) & $<0.05$ \\
\hline Solitary Abscess & $68 \%$ (C.I- 57.82\%-76.78\%) & 95.8\% (C.I 76.88\%-99.78\%) & $<0.05$ \\
\hline
\end{tabular}

Table 4: ROC curve analysis for INR, serum albumin and Leukocyte counts

\begin{tabular}{lllllllll}
\hline & Cut-off & Sensitivity & Specificity & LR+ & LR- & AUC & SE & P value \\
\hline INR & $>1.60$ & 100.00 & 93.42 & 15.20 & 0.00 & 0.997 & 0.008 & $<0.001^{* *}$ \\
Serum albumin & $<=1.90$ & 87.50 & 94.74 & 16.62 & 0.13 & 0.918 & $0.027^{*}$ & $<0.001^{* *}$ \\
Leukocyte counts & $>19200$ & 100.00 & 80.26 & 5.07 & 0.00 & 0.937 & $0.035^{*}$ & $<0.001^{* *}$ \\
\hline
\end{tabular}

Table 5: Comparison of expected to actual complications in patients with liver abscess

\begin{tabular}{|c|c|c|c|c|}
\hline Range of Score & $\begin{array}{c}\text { No of } \\
\text { Patients }\end{array}$ & Mean Score & $\begin{array}{c}\text { No of Complicated } \\
\text { cases }\end{array}$ & Clinical Significance \\
\hline$\overline{10-5}$ & 34 & $3.9(95 \%$ C.I 3.571- 4.229) & 0 & No or very low risk of complications \\
\hline $6-10$ & 64 & $8.1(95 \%$ C.I $7.875-8.325)$ & 4 & Mild to moderate risk of complications \\
\hline $11-15$ & 16 & $12.2(95 \%$ C.I $11.61-12.79)$ & 15 & High to grave risk of complications \\
\hline
\end{tabular}

$100 \%$ with complicated liver abscess and one point for those which had a statistically significant correlation with complicated liver abscess. Thus the score [Table 1] was applied to a validation cohort of 114 cases and the number of expected complications and actual complications was noted.

The validation cohort included 98 males and 16 females, of mean age 47.6 years ranging from 13 to 92 years. Early presentation was seen in 50 (43.8\%). Sub-acute presentation in 62 patients and late presentation in 2 cases. Eighty-one percent were alcoholic. $35 \%$ of patients had more than 10 years history of alcoholism. The most common initial manifestations were pain abdomen (100\%) and fever (90\%).

Comparison of expected to actual complications in patients with liver abscess according to the scoring system is shown in Table 5. Hence it was observed that the new scoring system was successful in identifying patients at risk of developing complications with $100 \%$ sensitivity and $93.75 \%$ specificity.

\section{Discussion}

Our study confirmed significant association of liver abscess with male gender, age group of fourth to fifth decade ${ }^{6-9}$ and alcohol consumption (both quantity and duration). ${ }^{10}$ The most frequent clinical findings were abdominal pain and fever similar to published literature ${ }^{6-8,11}$. Hepatomegaly was seen more often as compared to other series ${ }^{12}$. The major laboratory findings in our study were leukocytosis, raised levels of alkaline phosphatase, increased INR and hypo albuminemia. Raised alkaline phosphatase level and prolonged prothrombin time most often predicted complication of liver abscess in our study. In our series right pleural effusion was seen in most cases with3 cases rupturing into the right pleural cavity. Although solitary liver abscess involving the right lobe was common, proportion of multiple abscesses in our study was more compared to other studies ${ }^{12-14}$. Bammigatti et al ${ }^{15}$ considered 
Table 6: Clinical application of the predictive Score

\begin{tabular}{ll}
\hline $\begin{array}{l}\text { Patient classification } \\
\text { depending upon scores }\end{array}$ & Line of management recommended \\
\hline $\begin{array}{l}\text { Category A (0-5) } \\
\text { Category B (6-10) }\end{array}$ & $\begin{array}{l}\text { Medical therapy with follow up ultrasonography and other investigations } \\
\text { if needed therapeutic Aspiration of the abscess } \\
\text { Category C (11-15) }\end{array}$ \\
\hline
\end{tabular}

abscess diameter as the only parameter for deciding on treatment by conservative management or aspiration. Since this study takes into consideration many factors including ultrasongraphic volume of the abscess this scoring system tends to be superior to a single parameter.

In a prospective study, Sharma et al $^{16}$ considered multiple factors like bilirubin level $>3.5 \mathrm{mg} / \mathrm{dL}$, encephalopathy, volume of abscess cavity, hypoalbuminemia (serum albumin level <2.0 $\mathrm{g} / \mathrm{dL}$ ), and the number of abscesses. Some of this factors like volume of abscess cavity, hypoalbuminemia (serum albumin level $<2.0 \mathrm{~g} / \mathrm{dL}$ ), and the number of abscesses correlated with complications in our study also. However in the present study, other factors like INR and alcoholic history of more than 10 years were found to be strong predictors for complications. Another study by Sharma ${ }^{17}$ compared antibiotics vs. needle aspiration in patients with uncomplicated liver abscess and found that both had similar results. The present study can identify cases that may develop complications and which might need needle aspiration. It can better identify the ideal candidates for chemotherapy, which according to Sharma et al fall in group A in Table 6.

The predictive score used in this study correlated fairly well with the incidence of complications in liver abscess. The score can be used for identifying patients with risk of complications and hence aid in efficient management. The clinical dilemma of whether to perform a therapeutic aspiration along with medical therapy is solved by using the score advocated in this study. By using this score [Table 1], patients can be classified into three categories and the line of management modified accordingly. Clinical application of the predictive scoring system is shown in Table 6.

In conclusion, the predictive score suggests the lines of management preventing any clinical dilemma and avoiding unnecessary investigations and procedures for the patients. The current predictive score is being used in our institute and the results are excellent. We recommend that this score should become a part of standard of care for management of liver abscess worldwide.

\section{References}

1. Lee KT, Sheen PC, Chen JS. Pyogenicliver abscess: Multivariate analysis of risk factors. World Journal of Surgery. 1991;15:372-7.

2. Chu KM, Fan ST, Lai EC. Pyogenicliver abscess: Audit of experience over past decade. Archives of Surgery. 1996;131:148-52.

3. Meddings L, Myers RP, Hubbard J, Shaheen A, Laupland K, Dixon E, etal. Apopulation-based study of pyogenicliver abscesses in the United States: Incidence, mortality, and temporal trends. Am J Gastroenterol. 2010;105:117-24.

4. Ribaudo JM, Ochsner A. Intrahepatic abscesses: amebicandpyogenic. Am J Surg. 1973;125:570-4.

5. Rahimian J, Wilson T, Oram V, Holzman RS. Pyogenicliver abscess: recent trends in etiology and mortality. Clin Infect Dis. 2004;39:1654-9.

6. Huang CJ, Pitt HA, Lipsett PA, Osterman FA, Lillimoe KD, Cameron JL, et al. Pyogenichepatic abscess. Changing trends over 42 years. Ann Surg.1996;223:600-7.

7. Ribaudo JM, Ochsner A.Intrahepatic abscesses: amebic and pyogenic. Am J Surg. 1973;125:570-4.

8. Miedema BW, Dineen P. The diagnosis and treatment of pyogenicliver abscess. Ann Surg. 1984;200:328-35.

9. Chu KM, Fan ST, Lai EC, Lo CM, Wong J. Pyogenicliver abscess. An audit of experience over the past decade. Arch Surg.1996;131:148-52.

10. Shyam Mattur, Gehlot RS, Alok Mehta. Liver abscess. Journal of Indian Academy of Clinical Medicine. 2002;3:78-9.

11. Wong WM, Wong BC, Hui CK, Ng M, Lai KC, Tso WK, etal. Pyogenic liver abscess: retrospective analysis of 80 cases over a10-year period. J Gastroenterol Hepatol. 2002;17:1001-7.

12. Yoo HM, Kim WH, Shin SK, Chun WH, Kang JK, Park IS. The changing patterns of liver abscess during the past 20 years: a study of 482 cases. Yonsei Med J.1993;34:340-51.

13. Rajak CL, Gupta S, Chowla Y. Percutaneous treatment of liver abscess. American Journal of Roentgenology. 1998;170:1035-9.

14. Khan R, Hamid S, Abid S, Jafri W, Abbas Z, Islam M, et al. Predictive factors for early aspiration in liver abscess. World $J$ Gastroenterol. 2008;14:2089-93.

15. Bammigatti C, Ramasubramanian NS, Kadhiravan T, Das AK. Percutaneous needle aspiration in uncomplicated amebic liver abscess: a randomized trial. Trop Doct. 2013;43:19-22.

16. Sharma MP, Dasarathy S, Verma N, Saksena S, Shukla DK. Prognostic markers in amebic liver abscess: a prospective study. Am J Gastroenterol. 1996;91:2584-8.

17. Sharma MP, Rai RR, Acharya SK, Ray JC, Tandon BN. Needle aspiration of amoebic liver abscess. BMJ. 1989;299:1308-9. 